\title{
An intronic polymorphic deletion in the PTEN gene: implications for molecular diagnostic testing
}

\author{
S Sandell ${ }^{1}$, R J L Schuit ${ }^{2}$ and D J Bunyan ${ }^{*}, 1$ \\ ${ }^{1}$ Wessex Regional Genetics Laboratory, Salisbury District Hospital, Salisbury SP2 8BJ, UK and ${ }^{2}$ MRC-Holland, Willem \\ Schoutenstraat 6, 1057 DN Amsterdam, The Netherlands
}

Background: A cohort of 629 patients with suspected Bannayan-Riley-Ruvalcaba syndrome or Cowden syndrome was tested for mutations in the PTEN gene.

Methods: Dosage analysis of PTEN was carried out using a PTEN-specific multiplex ligation-dependent probe amplification (MLPA) kit, whereas point mutation analysis was performed using direct sequencing.

Results: Approximately 4\% of the patients from the testing cohort were heterozygously deleted for the two MLPA probe-binding sites situated in intron 1. The same deletion was subsequently seen in $\sim 3 \%$ of 220 normal controls, and in patients from the testing cohort with a causative mutation elsewhere in the PTEN gene. Sequencing of the variant revealed an $899 \mathrm{bp}$ deletion, the $3^{\prime}$ breakpoint of which is only $58 \mathrm{bp}$ from the start of exon 2.

Conclusion: Although all evidence suggests that the $899 \mathrm{bp}$ deletion is a polymorphism with no clinical effect, it removes the binding sites of almost all published PTEN exon 2 forward primers, resulting in allelic loss during PCR.

The PTEN tumour suppressor gene is involved in the phosphoinositol 3-kinase pathway and encodes a phosphatase with lipid and protein substrates, active in many pathways involved in cellular growth. The PTEN hamartoma tumour syndromes form a spectrum of autosomal dominantly inherited syndromes with variable clinical manifestations, the most commonly reported conditions being Cowden syndrome (CS) and Bannayan-RileyRuvalcaba syndrome (BRRS) (Arch et al, 1997; Liaw et al, 1997; Nelen et al, 1997), which have both been shown to be caused in part by germline PTEN mutations. Both are characterised by multiple hamartomas and have many overlapping features.

Dosage analysis is an important part of the PTEN screening strategy as large deletions are detected in $\sim 10 \%$ of point mutationnegative BRRS patients and have been reported in point mutationnegative CS patients (Zhou et al, 2003; Orloff and Eng, 2008). The method of choice for this analysis is the Multiplex Ligationdependent Probe Amplification (MLPA) assay (Schouten et al,
2002) and MRC-Holland (Amsterdam, The Netherlands) released a PTEN-specific kit (P225) in 2007. Analysis of the PTEN gene is made difficult by the existence of a highly homologous PTEN pseudogene, so for this MLPA kit many of the probes had to be situated in the PTEN introns, rather than the exons, in order to distinguish it from its pseudogene. The original P225 kit that was used in this study had three probes corresponding to exon 2 - two of them in intron 1 (with ligation sites at c.80-504 and c.80-219) and one in intron 2 (with a ligation site at position c.164+302).

In our study, MLPA dosage analysis of the PTEN gene was performed on a large cohort of patients with suspected BRRS or CS. A significant proportion of patients were found to be heterozygously deleted for just the two 'exon 2' probes that were located in intron 1. Subsequent testing was then performed in order to characterise the deletion, to determine its frequency in our test cohort and the general population, and to investigate its origins and any potential phenotypic effects. 


\section{MATERIALS AND METHODS}

Patients. A cohort of 629 probands with suspected BRRS or CS was collected at the Wessex Regional Genetics Laboratory over a period of 19 years following referrals from local, national and international clinicians.

In order to provide a matched control cohort, 220 healthy controls were chosen and anonymised. These individuals were the normal partners who had been carrier-tested for autosomal recessive conditions in the Wessex laboratory.

Multiplex ligation-dependent probe amplification analysis. The MLPA was carried out according to the manufacturer's instructions with the P225 (version A1) PTEN kit on the cohort of 629 BRRS/CS probands. The MLPA PCR products $(1 \mu \mathrm{l})$ were separated on an ABI3100 Sequencer and analysed using Genotyper (v3.7) software (Applied Biosystems, Foster City, CA, USA). PTEN intron/exon copy number was determined by exporting peak heights into an Excel spreadsheet, specifically designed to assess the ratio of each test peak relative to all other peaks for the given individual. Further, ratios of test:control peaks and control:control peaks for each sample were compared with normal individuals included in each run (Bunyan et al, 2004).

The PCR and Sequencing analysis. The PCR amplification of genomic DNA was performed using various combinations of primers from intron 1 and exon 2 of the PTEN gene to generate a fragment spanning the deletion breakpoint. A PCR product was generated using primers $5^{\prime}$-aaatcaactcaatcatgtgaaagc- $3^{\prime}$ (forward) and $5^{\prime}$-ggtgaccagcattttatggag- $3^{\prime}$ (reverse), which give a normalsized product of $1752 \mathrm{bp}$ and a smaller product of $853 \mathrm{bp}$ (see Figure 1). Reactions were carried out in a $25 \mu \mathrm{l}$ volume containing $50 \mathrm{ng}$ DNA, $1 \mu \mathrm{M}$ forward primer, $1 \mu \mathrm{M}$ reverse primer, $2.5 \mu \mathrm{l} 10 \times$ reaction buffer (Perkin Elmer, Waltham, MA, USA), $0.16 \mathrm{~mm}$ dNTPs, $1.5 \mathrm{~mm} \mathrm{MgCl}_{2}, 0.5 \mathrm{u}$ Taq polymerase (Taq Gold, Perkin Elmer). Cycling parameters were $94^{\circ} \mathrm{C}$ for $12 \mathrm{~min}$ followed by 35 cycles of $94{ }^{\circ} \mathrm{C}$ for $30 \mathrm{~s}, 60^{\circ} \mathrm{C}$ for $30 \mathrm{~s}$ and $72^{\circ} \mathrm{C}$ for $90 \mathrm{~s}$. The PCR

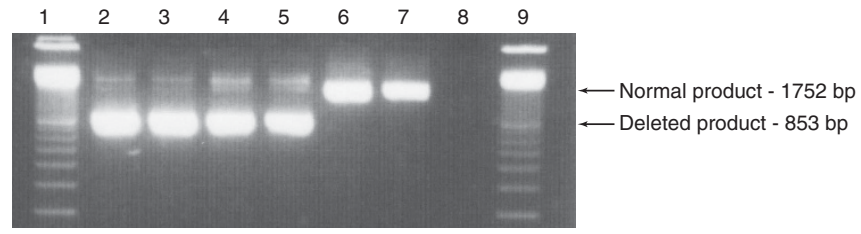

Figure 1. Agarose gel electrophoresis of the PCR products from the intron 1/exon 2 region. Lanes 1 and $9=$ size markers (100 bp ladder; Sigma, Gillingham, Dorset, UK), lanes $2-5=$ individuals with the intron 1 deletion variant, lanes 6 and $7=$ patients without the intron 1 deletion variant, lane $8=$ no DNA control. products were sequenced bidirectionally using the Big Dye Terminator v1.1 cycle sequencing kit (Applied Biosystems, Warrington, UK) and analysed using Mutation Surveyor software version 3.2 (Soft Genetics, State College, PA, USA). All patients with the intron 1 deletion were sequenced.

Subsequent intron 1 deletion analysis of a cohort of 220 normal individuals was carried out using this PCR assay. All control individuals with the intron 1 deletion were also sequenced.

PTEN linkage. We were able to perform haplotype analysis on 20 of the 26 deletion-positive patients from the BRRS/CS cohort to look for a common haplotype. This was done with the CA repeat markers D10S215 and D10S541, which closely flank the PTEN gene, using previously published primers and conditions (Feilotter et al, 1999). As the deletion-positive patients from the control group had been anonymised, these were not included in the linkage study.

\section{RESULTS}

The MLPA analysis of the BRRS/CS cohort showed that 26 of the 629 patients $(4 \%)$ had the intron 1 deletion (MLPA raw data not shown). Sequence analysis showed that this deletion was $899 \mathrm{bp}$ in size and was situated $58 \mathrm{bp}$ from the start of exon 2, c.80-956_-58del899 (HGVS nomenclature using RefSeq NM_000314.4, see Figure 2). The deletion includes the ligation sites of the two intron 1 P225-A1 MLPA probes (see Figure 3). All 26 apparently unrelated patients had identical sequencing breakpoints. Twenty-five of these deletion-positive cases were of British origin and one was of Turkish heritage.

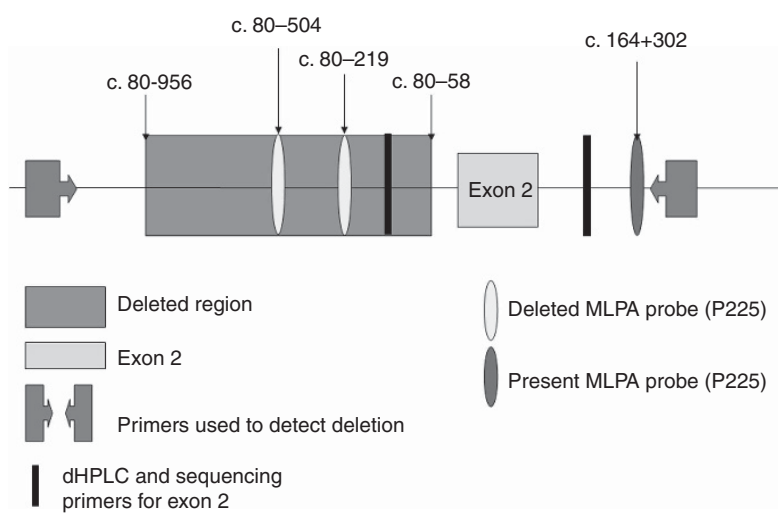

Figure 3. Schematic showing the position of the intron 1 deletion, the affected MLPA probe binding sites and the location of primer pairs within the PTEN gene.

\section{A}

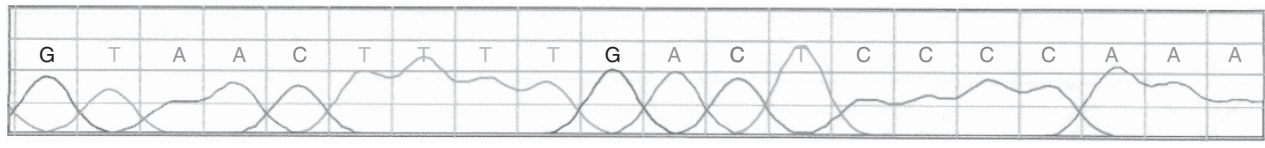

B

899 bp Deletion

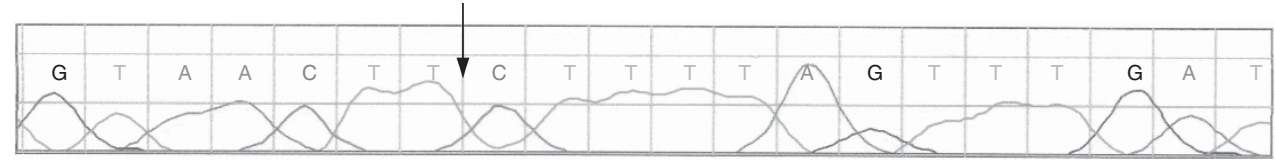

Figure 2. Sequence chromatograms from a normal individual (A) and an individual with the intron 1 deletion variant (B). The position of the deleted bases is marked with an arrow. 
Six of the 26 deletion-positive patients also had a causative point mutation or frameshift mutation elsewhere in the PTEN gene. In one of these six cases we know that the intronic deletion and the other point mutation (an exon 2 splice donor site mutation, c. $164+1 \mathrm{G}>\mathrm{A}$ ) are in trans as PCR amplification of exon 2 using a forward primer from within the intron 1 deletion solely amplified the allele containing the splice site mutation. Owing to the lack of parental samples, we were unable to determine phase in the other five cases.

Intron 1 PCR analysis of the 220 normal controls showed that six individuals (3\%) also had the 899 bp deletion, confirmed by sequencing to be identical to that seen in the BRRS/CS cohort. Although the control samples were anonymised before testing, all patients in that cohort were completely healthy at the time of DNA extraction with no known symptoms of BRRS or CS.

Haplotype analysis using markers D10S215 and D10S541 showed no evidence that the intron 1 deletion is a founder mutation. Allele sizes from the 20 apparently unrelated deletionpositive patients from the BRRS/CS cohort were extremely widespread. For these 20 individuals the deletion was found to be associated with a minimum of 11 haplotypes and a maximum of 19 (data not shown).

\section{DISCUSSION}

There is no obvious mechanism that would cause the recurrence of this $899 \mathrm{bp}$ deletion from intron 1 of the PTEN gene. The deleted segment has no large quasipalindromic sequences and no flanking repeats, whereas the MFOLD DNA folding prediction software (www.mfold.rna.albany.edu/) suggests that the breakpoints are not in exposed parts of hairpin loops, nor does the deleted segment form a hairpin loop itself.

Alamut mutation interpretation software (www.interactivebiosoftware.com/alamut) predicts the replacement of multiple essential splice elements and proposes a cryptic splice acceptor site at position c.80-50, but although multiple PTEN transcripts have been reported (Sharrard and Maitland, 2000; Sarquis et al, 2006), none of them report a loss of exon 2 or the inclusion of a larger exon 2 because of the use of this potential cryptic acceptor site. Other groups have studied PTEN RNA transcripts from individuals with this polymorphism and no effect on splicing was observed (Reviewer 3, personal communication).

As the deletion is present in healthy individuals, and in patients with a known causative PTEN mutation in trans, we can conclude that this variant has no phenotypic effect, but it does result in a potential problem for point mutation analysis if it is not detected. To allow the detection of possible splice site mutations and to get full exonic coverage, it is common practice to site PCR primers at least $50 \mathrm{bp}$ outside of exons. Most of the published PTEN exon 2 forward primers lie within the intron 1 deletion variant (e.g. Liaw et al, 1997; Marsh et al, 1997; Steck et al, 1997; Minaguchi et al, 2001; Silva et al, 2008), so these primers would only amplify one allele of exon 2 in a patient with the intronic deletion, and would also affect any method based on heteroduplex analysis.

The results from the linkage analysis were surprising. It was expected that the intron 1 variant would be associated with a common haplotype with the closely flanked markers D10S215 and D10S541, but the haplotypes in the 20 patients with the $899 \mathrm{bp}$ deletion were essentially random. However, it is still possible that this is an extremely old founder mutation that has been through enough meioses to cause such variability in the flanking CA repeats. Mutations in several genes, e.g. CFTR and BRCA1, have been shown to persist for hundreds of generations (Morral et al, 1994; Neuhausen et al, 1996). The cross-over rates between the D10S215 and D10S541 markers and the PTEN gene are both 1\%
(Leal and Da-Silva, 1999), and CA repeat allele sizes have been previously shown to change meiotically (Kwiatkowski and Diaz, 1992). Although most of our cohort is of British origin, the intron 1 variant was seen in one patient of Turkish origin and was also seen in Canada (Jan Schouten, MRC-Holland, personal communication) and America (both African Americans and Caucasian Americans; Reviewer 3, personal communication), suggesting that this variant is present worldwide, supporting the theory that it may have existed for many generations.

There is a paucity of reported polymorphic intronic deletion variants so close to an exon. Curiously, the only other published example is also in the PTEN gene - a 39 bp deletion polymorphism in intron 7 in African American patients which has a $3^{\prime}$ breakpoint $15 \mathrm{bp}$ from the start of exon 8 (Zhou et al, 2002). Is this a quirk of the PTEN gene, or are other genes similarly affected but current methodology does not detect such variants? As most dosage detection techniques tend to focus on the exons, any intronic variability may go undetected.

The current commercial PTEN MLPA kit from MRC-Holland (P225 version B2) no longer detects the intron 1 variant as the two probes from the original version of the kit that were within the deleted area have now been moved, so it is important that another method is used to detect this variant. Any patients that were previously screened for point mutations in exon 2 of the gene using a forward primer from within the potentially deleted intron 1 region should now be retested in light of this finding. Here we provide a simple PCR-based test for the deletion variant that will easily detect any deletion carriers that will need to be re-sequenced with a new forward primer that lies within 58 bases of exon 2. In our cohort of BRRS/CS patients, exon 2 point mutations account for $11 \%$ of all PTEN mutations (10 out of 89 positive patients), therefore a significant number of mutations may have been missed due to non-amplification of an allele during PCR.

\section{ACKNOWLEDGEMENTS}

We thank the clinicians who supplied our cohort of BRRS and CS patients.

\section{CONFLICT OF INTEREST}

The authors declare no conflict of interest.

\section{REFERENCES}

Arch EM, Goodman BK, Van Wesep RA, Liaw D, Clarke K, Parsons R, McKusick VA, Geraghty MT (1997) Deletion of PTEN in a patient with Bannayan-Riley-Ruvalcaba syndrome suggests allelism with Cowden disease. Am J Med Genet 71: 489-493.

Bunyan DJ, Eccles DM, Sillibourne J, Wilkins E, Thomas NS, Shea-Simonds J, Duncan PJ, Curtis CE, Robinson DO, Harvey JF, Cross NC (2004) Dosage analysis of cancer predisposition genes by multiplex ligation-dependent probe amplification. Br J Cancer 91(6): 1155-1159.

Feilotter HE, Coulon V, McVeigh JL, Boag AH, Dorion-Bonnet F, Duboué B, Latham WCW, Eng C, Mulligan LM, Longy M (1999) Analysis of the $10 \mathrm{q} 23$ chromosomal region and the PTEN gene in human sporadic breast carcinoma. Br J Cancer 79(5/6): 718-723.

Kwiatkowski DJ, Diaz MO (1992) Dinucleotide repeat polymorphism at the IFNA locus (9p22). Hum Mol Genet 1(8): 658.

Leal GF, Da-Silva EO (1999) Limb-girdle muscular dystrophy with apparently different clinical courses within sexes in a large inbred kindred. J Med Genet 36: 714-718.

Liaw D, Marsh DJ, Li J, Dahia PL, Wang SI, Zheng Z, Bose S, Call KM, Tsou HC, Peacocke M, Eng C, Parsons R (1997) Germline mutations of 
the PTEN gene in Cowden disease, an inherited breast and thyroid cancer syndrome. Nat Genet 16: 64-67.

Marsh DJ, Roth S, Lunetta KL, Hemminki A, Dahia PLM, Sistonen P, Zheng Z, Caron S, van Orsouw NJ, Bodmer WF, Cottrell SE, Dunlop MG, Eccles D, Hodgson SV, Jarvinen H, Kellokumpu I, Markie D, Neale K, Phillips R, Rozen P, Syngal S, Vijg J, Tomlinson IPM, Aaltonen LA, Eng C (1997) Exclusion of PTEN and 10q22-24 as the susceptibility locus for juvenile polyposis syndrome. Cancer Res 57: 5017-5021.

Minaguchi T, Yoshikawa H, Oda K, Ishino T, Yasugi T, Onda T, Nakagawa S, Matsumoto K, Kawana K, Taketani Y (2001) PTEN mutation located only outside exons 5, 6, and 7 is an independent predictor of favorable survival in endometrial carcinomas. Clin Cancer Res 7: 2636-2642.

Morral N, Bertranpetit J, Estivill X, Nunes V, Casals T, Giménez J, Reis A, Varon-Mateeva R, Macek Jr. M, Kalaydjieva L, Angelicheva D, Dancheva R, Romeo G, Russo MP, Garnerone S, Restagno G, Ferrari M, Magnani C, Claustres M, Desgeorges M, Schwartz M, Schwarz M, Dallapiccola B, Novelli G, Ferec C, de Arce M, Nemeti M, Kere J, Anvret M, Dahl N, Kadasi L (1994) The origin of the major cystic fibrosis mutation ( $\Delta \mathrm{F} 508)$ in European populations. Nat Genet 7: 169-175.

Nelen MR, van Staveren WC, Peeters EA, Hassel MB, Gorlin RJ, Hamm H, Lindboe CF, Fryns JP, Sijmons RH, Woods DG, Mariman EC, Padberg GW, Kremer H (1997) Germline mutations in the PTEN/MMAC1 gene in patients with Cowden disease. Hum Mol Genet 6: 1383-1387.

Neuhausen SL, Mazoyer S, Friedman L, Stratton M, Offit K, Caligo A, Tomlinson G, Cannon-Albright L, Bishop T, Kelsell D, Solomon E Weber B, Couch F, Struewing J, Tonin P, Durocher F, Narod S, Skolnick MH, Lenoir G, Serova O, Ponder B, Stoppa-Lyonnet D, Easton D, King MC, Goldgar DE (1996) Haplotype and phenotype analysis of six recurrent BRCA1 mutations in 61 families: results of an international study. Am J Hum Genet 58: 271-280.

Orloff MS, Eng C (2008) Genetic and phenotypic heterogeneity in the PTEN hamartoma tumour syndrome. Oncogene 27: 5387-5397.

Sarquis MS, Agrawal S, Shen L, Pilarski R, Zhou XP, Eng C (2006) Distinct expression profiles for PTEN transcript and its splice variants in Cowden syndrome and Bannayan-Riley-Ruvalcaba syndrome. Am J Hum Genet 79(1): 23-30.

Schouten JP, McElgunn CJ, Waaijer R, Zwijnenburg D, Diepvens F, Pals G (2002) Relative quantification of 40 nucleic acid sequences by multiplex ligation-dependent probe amplification. Nuc Acid Res 30: e57.

Sharrard RM, Maitland NJ (2000) Alternative splicing of the human PTEN/ MMAC1/TEP1 gene. Bioch Biophys Acta 1494(3): 282-285.

Silva A, Yunes JA, Cardoso BA, Martins LR, Jotta PY, Abecasis M, Nowill AE, Leslie NR, Cardoso AA, Barata JT (2008) PTEN posttranslational inactivation and hyperactivation of the PI3K/Akt pathway sustain primary T cell leukemia viability. J Clin Invest 118(11): 3762-3774.

Steck PA, Pershouse MA, Jasser SA, Yung WKA, Lin H, Ligon AH, Langford LA, Baumgard ML, Hattier T, Davis T, Frye C, Hu R, Swedlund B, Teng DHF, Tavtigian SV (1997) Identification of a candidate tumour suppressor gene, $M M A C 1$, at chromosome 10q23.3 that is mutated in multiple advanced cancers. Nat Genet 15: 356-362.

Zhou XP, Hampel H, Roggenbuck J, Saba N, Prior TW, Eng C (2002) A 39-bp deletion polymorphism in PTEN in African American Individuals. $J \mathrm{Mol}$ Diag 4(2): 114-118.

Zhou XP, Waite KA, Pilarski R, Hampel H, Fernandez MJ, Bos C, Dasouki M, Feldman GL, Greenberg LA, Ivanovich J, Matloff E, Patterson A, Pierpont ME, Russo D, Nassif NT, Eng C (2003) Germline PTEN promoter mutations and deletions in Cowden/Bannayan-Riley-Ruvalcaba syndrome result in aberrant PTEN protein and dysregulation of the phosphoinositol-3-kinase/Akt pathway. Am J Hum Genet 73: 404-411.

This work is published under the standard license to publish agreement. After 12 months the work will become freely available and the license terms will switch to a Creative Commons AttributionNonCommercial-Share Alike 3.0 Unported License. 